University of Nebraska - Lincoln

DigitalCommons@University of Nebraska - Lincoln

Agronomy \& Horticulture -- Faculty Publications

Agronomy and Horticulture Department

2007

\title{
Fertility Restoration of the Sorghum A3 Male-Sterile Cytoplasm through a Sporophytic Mechanism Derived from Sudangrass
}

\author{
Hoang V. Tang \\ University of Florida \\ Jeffrey F. Pedersen \\ University of Nebraska-Lincoln, jpedersen1@unl.edu \\ Christine D. Chase \\ University of Florida, cdchase@ufl.edu \\ Daryl R. Pring \\ University of Florida
}

Follow this and additional works at: https://digitalcommons.unl.edu/agronomyfacpub

Part of the Agricultural Science Commons, Agriculture Commons, Agronomy and Crop Sciences Commons, Botany Commons, Horticulture Commons, Other Plant Sciences Commons, and the Plant Biology Commons

Tang, Hoang V.; Pedersen, Jeffrey F.; Chase, Christine D.; and Pring, Daryl R., "Fertility Restoration of the Sorghum A3 Male-Sterile Cytoplasm through a Sporophytic Mechanism Derived from Sudangrass" (2007). Agronomy \& Horticulture -- Faculty Publications. 936.

https://digitalcommons.unl.edu/agronomyfacpub/936

This Article is brought to you for free and open access by the Agronomy and Horticulture Department at DigitalCommons@University of Nebraska - Lincoln. It has been accepted for inclusion in Agronomy \& Horticulture -Faculty Publications by an authorized administrator of DigitalCommons@University of Nebraska - Lincoln. 


\title{
Fertility Restoration of the Sorghum A3 Male-Sterile Cytoplasm through a Sporophytic Mechanism Derived from Sudangrass
}

\author{
Hoang V. Tang, Jeffrey F. Pedersen, Christine D. Chase, and Daryl R. Pring^
}

\begin{abstract}
Fertility restoration of sorghum [Sorghum bicolor (L.) Moench] lines carrying the IS1112C (A3 group) male-sterile cytoplasm has been documented as a two-gene gametophytic mechanism involving complementary action of restoring alleles designated $R f 3$ and $R f 4$, as derived from IS1112C. Fertility restoration capability has also been reported from sudangrass (S. bicolor subsp. drummondii) populations. We describe characteristics of a fertility restoration system derived from sudangrass, in which male-sterile individuals were observed at high frequency in backcross and $F_{2}-F_{3}$ segregating populations. Segregation analyses were consistent with a sporophytic restoration system involving two complementary genes. Pollen iodine staining in fertile progeny indicated that the restorers were not efficacious, and fertility was decreased in progeny of backcrosses. Silencing of restoring alleles through paramutation might be operative in these examples. Sudangrass-derived fertility restoration did not involve enhanced transcript processing of the chimeric mitochondrial open reading frame orf107. Thus male sterility induced by the A3 cytoplasm can be restored through different mechanisms.
\end{abstract}

H.V. Tang and D.R. Pring, USDA-ARS, Chemistry Research Unit, CMAVE, c/o Dep. of Plant Pathology, 1453 Fifield Hall, Univ. of Florida, Gainesville, FL 32611; J.F. Pedersen, USDA-ARS, Grain, Forage, and Bioenergy Research Unit, c/o Dep. of Agronomy, Univ. of Nebraska-Lincoln, Lincoln, NE 68583-0937; C.D. Chase, Horticultural Sciences Dep., Univ. of Florida, Gainesville, FL 32611. Received 25 Aug. 2006. *Corresponding author (drpg@ufl.edu).

Abbreviations: CMS, cytoplasmic-nuclear male sterility; F, male-fertile; S, male-sterile; TPA, transcript processing activity.

$\mathrm{H}$ YBRID GRAIN sorghum [Sorghum bicolor (L.) Moench] production in the USA is essentially dependent on one source of cytoplasmic-nuclear male sterility (CMS), the milo or A1 source (Pring et al., 1995; Schertz et al., 1997). Seven malesterile cytoplasm groups have been defined based on differential fertility restoration requirements (Xu et al., 1995; Schertz et al., 1997). Among these groups is sterility conferred by cytoplasm of the line IS1112C (type member, A3 group). This source of CMS has not been commercially utilized for hybrid seed production because of the low frequency of restorer genes among sorghum lines and lines developed through the Sorghum Conversion Program (Worstell et al., 1984; Bosques-Vega et al., 1989; Torres-Cardona et al., 1990; Schertz et al., 1997; Kuhlman et al., 2006). Genetic analyses of fertility restoration in the A3 source of CMS lead to the determination that restoration conferred by the male-fertile source of the cytoplasm, IS1112C, was through a gametophytic mechanism requiring complementary action of two restoring alleles designated $R f 3$ and $R f 4$ (Tang et al., 1996b, 1998; Pring et al., 1999). In gametophytic restoration, the haploid pollen must carry restoring alleles to function. Only restoring

Published in Crop Sci. 47:943-950 (2007).

doi: 10.2135/cropsci2006.08.0542

(C) Crop Science Society of America

677 S. Segoe Rd., Madison, WI 53711 USA

All rights reserved. No part of this periodical may be reproduced or transmitted in any form or by any means, electronic or mechanical, including photocopying, recording, or any information storage and retrieval system, without permission in writing from the publisher. Permission for printing and for reprinting the material contained herein has been obtained by the publisher. 
alleles are transmitted through the paternal parent, and all resulting progeny are male fertile.

The mitochondrial chimeric open reading frame orf107 is associated with CMS conferred by IS1112C (Tang et al., 1996b, 1998). In male-fertile $F_{1}$ populations of A3Tx398/ IS1112C and A3Tx7000/IS1112C, an enhanced transcript processing activity (TPA) is evident, cleaving about $75 \%$ of orf107 transcripts within the open reading frame, reducing the abundance of full-length transcripts available for possible translation (Tang et al., 1996a, 1998). Segregation analyses indicated that enhanced TPA was required for fertility restoration, leading to the conclusion that enhanced TPA was tightly linked to, or represented action of, a restoring allele, which was assigned to $R f 3$ (Tang et al., 1998; Pring et al., 1999). Enhanced orf107 TPA is linked to the single dominant gene Mmt1, which confers enhanced transcript processing 5' to the mitochondrial gene atp4 (orf25); IS1112C is Mmt1, while A3Tx398 is mmt1 (Tang et al., 1996b, 1998). Designation of the restoring alleles as dominant is tentative because restoration occurs in haploid tissues. No mechanism has been established for Rf4 in restoration, but the rf 4 locus has been mapped and assigned to linkage group E, or chromosome 7 (Wen et al., 2002; Kim et al., 2005).

Fertility restoration capability for the A3 male-sterile cytoplasm has also been identified in some populations of sudangrass (S. bicolor subsp. drummondii) (Pedersen and Toy, 1997), wherein 14\% seed set was observed in A3Tx398 $\times$ sudangrass $F_{1}$ hybrids. Additionally, fertility restoration of A3 male-sterile cytoplasm was observed in a small number of lines (4 of 1007) derived from openpollinated progeny of A3Tx398 and A3KS57 $F_{1}$ hybrids produced in near proximity to shattercane (S. bicolor subsp. drummondii) (Pedersen et al., 2003).

We report here the recovery and characterization of fertility restoration capability for the A3 male-sterile cytoplasm resulting from bulk pollinations with the NP28 and NP35 sudangrass populations. The molecular and genetic features of sudangrass-derived restoration are distinct from those of the two-gene gametophytic restoration mechanism conferred by IS1112C.

\section{MATERIALS AND METHODS}

All data reported here were obtained from plants grown in field plots near Gainesville, FL, during the period 1997-2006. Panicles to be used for crosses were bagged on emergence. Plants to be used for backcrossing to A3Tx398 and for self-pollination were selected after pollen iodine staining. Since starch amylose deposition in pollen grains is initiated about $72 \mathrm{~h}$ before anthesis (Pring and Tang, 2004), pollen was collected and stained with iodine about $24 \mathrm{~h}$ before anther exsertion. Seed set under pollinating bags was visually estimated at maturity.

\section{Generation of Self and Backcross Populations}

Sudangrass individuals from the populations NP28 (Gorz et al., 1990a) and NP35 (Gorz et al., 1990b) that restored fertil- ity to A3 CMS were identified by crossing them to A3Tx398 or A3Tx430 and observing subsequent seed set at Lincoln, NE. These individuals were simultaneously self-pollinated by covering panicles with pollinating bags before anthesis. Two $\mathrm{S}_{1}$ (male-sterile) lines from parents with A3 CMS restoration capability were identified from each population and designated NP28S -1 , NP28S -2 , NP35S -1 , and NP35S -2 .

To capture and characterize this new source of restoration, these $\mathrm{S}_{1}$ lines were grown and utilized for bulk pollinations of A3Tx398 at Gainesville, FL. Five fertile $F_{1}$ populations were grown and self-pollinated, and $193 \mathrm{~F}_{2}$ panicles were scored for fertile:sterile plants. Pollen staining of 80 plants from the $F_{2}$ families revealed numerous individuals with $>95 \%$ staining, and one such individual was selected for advance. Among individuals in this $\mathrm{F}_{3}$ population, two plants with 95\% stained pollen were self-pollinated and crossed to A3Tx398. These plants were designated 14M18 and 14M21.

\section{Development of 14M18 Progeny}

The 14M18 individual was self-pollinated, generating the $\mathrm{F}_{4}$ population designated S04-28. A3Tx398 was pollinated with $14 \mathrm{M} 18$, generating a $\mathrm{BC}_{1} \mathrm{~F}_{1}$ population; among these plants, an individual designated 24-65 was selected and used to pollinate A3Tx398, generating the $\mathrm{BC}_{2} \mathrm{~F}_{1}$ S04-29. Individual 24-65 was also self-pollinated, generating the $\mathrm{BC}_{1} \mathrm{~F}_{2}$ population S04-30. Two individuals from the $\mathrm{BC}_{1} \mathrm{~F}_{2} \mathrm{~S} 04-30$ population with greater than $80 \%$ pollen staining were selected for self-pollination and backcrossing to A3Tx398. One of those individuals, S04-30-69, was self-pollinated to generate the $\mathrm{BC}_{1} \mathrm{~F}_{3}$ population $\mathrm{S} 05-35$. A backcross to A3Tx398 generated the $\mathrm{BC}_{2} \mathrm{~F}_{1}$ population $\mathrm{S} 05-36$. The second individual from the $\mathrm{BC}_{1} \mathrm{~F}_{2} \mathrm{~S} 04-30$, S04-30-200 was self-pollinated to generate the $\mathrm{BC}_{1} \mathrm{~F}_{3}$ population $\mathrm{S} 05-37$. A backcross to A3Tx398 generated the $\mathrm{BC}_{2} \mathrm{~F}_{1}$ population $\mathrm{S} 05-38$.

The $\mathrm{BC}_{1} \mathrm{~F}_{3}$ population $\mathrm{S} 05-37$ was examined for pollen staining, and 16 individuals were self-pollinated to generate $\mathrm{BC}_{1} \mathrm{~F}_{4}$ families. These families were grown, and 8 to 10 individuals in each family were examined for pollen staining and seed set. Two individuals from one family, each with $100 \%$ pollen staining, were backcrossed to A3Tx398, generating two $\mathrm{BC}_{2} \mathrm{~F}_{1}$ populations, and self-pollinated to generate two $\mathrm{BC}_{1} \mathrm{~F}_{5}$ lines.

\section{Development of 14M21 Progeny}

The 14M21 individual was self-pollinated to generate a $\mathrm{F}_{4}$ population. A3Tx398 was pollinated with 14M21, generating the $\mathrm{BC}_{1} \mathrm{~F}_{1}$ population $\mathrm{S} 03-25$. Among the $\mathrm{S} 03-25$ population, an individual, designated 25-69 was identified, with $80 \%$ pollen staining and 30\% seed set. A3Tx398 was pollinated with 25-69, generating the $\mathrm{BC}_{2} \mathrm{~F}_{1}$ population S04-26. A second backcross was made with another individual, designated 25-72, which had $80 \%$ pollen staining and $90 \%$ seed set. This cross generated the $\mathrm{BC}_{2} \mathrm{~F}_{1}$ population $\mathrm{S} 04-27$.

\section{Transcript Analyses}

Plants near anthesis were examined for iodine pollen staining. Leaf RNA from fertile plants was prepared as described (Tang et al., 1998), and RNA from the equivalent of $2.5 \mathrm{~g}$ fresh weight was electrophoresed in agarose gels, blotted to membranes, and hybridized as described (Tang et al., 1996a). The membranes were probed with the orf107 clone pHC104, which spans orf107 
Table 1. Percentage seed set among lines derived from pollination of A3Tx398 with the individuals $14 \mathrm{M} 18$ and $14 \mathrm{M} 21$, and derived progenies. Values are numbers of plants with estimated percentage seed set. For comparison, the $F_{1}$ A3Tx398/IS1112C is included. Line designations and identifications are described in the text.

\begin{tabular}{|c|c|c|c|c|c|c|c|c|c|c|c|c|c|c|c|c|}
\hline & \multicolumn{13}{|c|}{ Percentage seed set } & \multirow[b]{2}{*}{ Total } & \multirow[b]{2}{*}{$F: S$} & \multirow[b]{2}{*}{ Mean seed set } \\
\hline & 100 & 90 & 80 & 70 & 60 & 50 & 40 & 30 & 20 & 10 & 5 & 1 & 0 & & & \\
\hline \multicolumn{17}{|l|}{ M18 lines } \\
\hline $\mathrm{F}_{4}(\mathrm{SO} 4-28)$ & & 22 & 17 & 4 & 1 & 4 & 3 & 1 & 2 & 1 & 4 & 2 & 31 & 92 & $61: 31$ & 67 \\
\hline $\mathrm{BC}_{2} \mathrm{~F}_{1}(\mathrm{~S} 04-29)$ & & & 1 & 1 & 2 & 1 & 0 & 3 & & & 1 & 2 & 48 & 59 & $11: 48$ & 38 \\
\hline $\mathrm{BC}_{1} \mathrm{~F}_{2}(\mathrm{~S} 04-30)$ & 2 & 18 & 10 & 2 & 1 & 6 & 1 & 1 & 4 & 3 & 1 & 5 & 34 & 88 & $54: 34$ & 61 \\
\hline $\mathrm{BC}_{1} \mathrm{~F}_{3}(\mathrm{~S} 05-35)$ & 1 & 16 & 9 & 2 & 1 & 2 & 2 & 3 & 3 & 2 & 1 & & 29 & 71 & $42: 29$ & 67 \\
\hline $\mathrm{BC}_{2} \mathrm{~F}_{1}(\mathrm{~S} 05-36)$ & & & & 2 & & 1 & & 1 & 2 & & & 3 & 47 & 56 & $9: 47$ & 29 \\
\hline $\mathrm{BC}_{1} \mathrm{~F}_{3}(\mathrm{~S} 05-37)$ & 5 & 26 & 9 & 4 & 1 & 2 & 1 & 1 & 1 & 1 & & 1 & 20 & 72 & $52: 20$ & 79 \\
\hline $\mathrm{BC}_{2} \mathrm{~F}_{1}(\mathrm{~S} 05-38)$ & & & 2 & 1 & & 1 & & 2 & & 1 & & 1 & 56 & 64 & $8: 56$ & 44 \\
\hline $\mathrm{BC}_{2} \mathrm{~F}_{1}(\mathrm{~S} 06-17)$ & & 1 & 8 & 2 & & 3 & & 1 & & & & & 0 & 15 & 15:0 & 70 \\
\hline $\mathrm{BC}_{2} \mathrm{~F}_{1}(\mathrm{~S} 06-19)$ & & 4 & 6 & 1 & 1 & 2 & & & & & & & 0 & 14 & 14:0 & 71 \\
\hline \multicolumn{17}{|l|}{ M21 Lines } \\
\hline $\mathrm{F}_{4}(\mathrm{~S} 01-30)$ & 10 & 6 & 7 & & & 8 & & 2 & & & & 3 & 3 & 39 & $36: 3$ & 71 \\
\hline $\mathrm{F}_{4}(\mathrm{SO} 4-25)$ & & 5 & 10 & 2 & 2 & 4 & 2 & & 2 & 1 & & 1 & 1 & 30 & $29: 1$ & 64 \\
\hline $\mathrm{BC}_{1} \mathrm{~F}_{1}(\mathrm{SO}-25)$ & 17 & 16 & 10 & 4 & 6 & 6 & & 1 & 2 & & & & & 62 & $62: 0$ & 83 \\
\hline $\mathrm{BC}_{2} \mathrm{~F}_{1}(\mathrm{~S} 04-26)$ & & & 1 & & & 1 & & & 1 & & & 2 & 26 & 31 & $5: 26$ & 30 \\
\hline $\mathrm{BC}_{2} \mathrm{~F}_{1}(\mathrm{SO} 04-27)$ & & & & & & & & & & & & 2 & 38 & 40 & $2: 38$ & 1 \\
\hline \multicolumn{17}{|l|}{ A3T×398/IS1112C } \\
\hline $\mathrm{F}_{1}(\mathrm{~S} 00-13)$ & {$[>90$} & & 44 & 36 & 19 & 15 & 13 & 13 & 9 & 8 & {$[<1$} & 10] & 1 & 205 & 204:1 & 61 \\
\hline
\end{tabular}

and carries sequences of atp9 (Tang et al., 1996b). Membranes were also probed the clone pHT160 to detect activity of the single dominant gene Mmt1, which is tightly linked or allelic to enhanced orf107 TPA, and confers enhanced TPA 5' to the mitochondrial gene atp 4 (orf25) (Tang et al., 1996a, 1998).

\section{RESULTS}

\section{Evaluation of Progenies Derived from Self-Pollinations}

Scoring of seed set in $42 \mathrm{~F}_{1}$ 's, representing 6 to 8 plants from each of the six crosses of A3Tx398 with NP28S -1 , $\mathrm{NP}_{28 S_{1}}-2, \mathrm{NP}_{3} \mathrm{~S}_{1}-1$, and $\mathrm{NP}_{3} \mathrm{~S}_{1}-2$, revealed no seed set in 26 panicles and 5- to 100\% seed set in the remaining 16 panicles. Therefore individuals within the four $S_{1}$ sudangrass lines transmitted fertility restoration capability, which was observed in $\mathrm{F}_{1}$ 's from five of the six original crosses to A3Tx398. $F_{2}$ families from each of the five fertile $F_{1}$ 's were scored for fertile:sterile plants. The five $\mathrm{F}_{2}$ families segregated 36F (fertile):19S (sterile), 27F:10S, 31F:9S, 20F:6S, and $22 \mathrm{~F}: 13 \mathrm{~S}$ plants. The high frequency of male-sterile plants observed, 22 to $37 \%$, is consistent with a sporophytic restoration mechanism, and not a gametophytic mechanism, wherein male-sterile plants are extremely rare among $\mathrm{F}_{2}$ 's resulting from pollination of A3Tx398 with IS1112C (Tang et al., 1996a, 1998; Pring et al., 1999). Examinations of 80 plants from these $\mathrm{F}_{2}$ families revealed 66 with stained pollen, consistent with seed set data. Of the 66 plants, 41 exhibited 50 to $100 \%$ stained pollen, indicating that efficacy of the restoration mechanism was such that not all pollen grains were apparently viable.

\section{Evaluation of 14M18 Progeny}

The 14M18 $\mathrm{F}_{4}$ population designated S04-28 segregated 61F:31S plants (Table 1), consistent with an $\mathrm{F}_{3}$ parent heterozygous for fertility restoration alleles. The mean seed set was $67 \%$, skewed toward a high percentage seed set, but seven individuals were scored at less than $10 \%$ seed set. We evaluated these data in comparison to fertility restoration conferred by IS1112C by scoring $205 \mathrm{~F}_{1}$ 's resulting from pollination of A3Tx398 with IS1112C (Table 1). These heterozygous $R f 3 r f 3 R f 4 r f 4 \mathrm{~F}_{1}$ 's are predicted to shed 25\% viable pollen (Tang et al., 1998; Pring et al., 1999) and exhibit approximately 50\% seed set (Worstell et al., 1984). We observed 61\% mean seed set in this $F_{1}$ population, which included 10 plants with less than $10 \%$ seed set, and one sterile plant. Thus, highly variable percentage seed set was observed within an $\mathrm{F}_{1}$ population that is assumed to genetically homogeneous. This variability in seed set was similar to that observed within the $\mathrm{F}_{4} \mathrm{SO} 4$ 28. Consequently we included individuals with very low seed set resulting from sudangrass-derived restoration in the "fertile" category. Chi-square analysis of the $\mathrm{F}_{4} \mathrm{SO} 4$ 28 population indicated that the segregation ratio fit $3: 1$ and 9:7 ratios (Table 2 ).

Pollination of A3Tx398 with 14M18 generated a $\mathrm{BC}_{1} \mathrm{~F}_{1}$ population. Among 19 of 27 fertile plants examined from this population, 10 had 70 to $90 \%$ stained pollen while 9 had less than 60\% staining. Thus, the population included many individuals with pollen staining clearly exceeding the expected 25\% stained pollen associated with the gametophytic restoration mechanism conferred 
Table 2. Analyses of segregation of male-fertile and male-sterile A3 cytoplasm sorghum backcross and selfed lines resulting from pollination with sudangrass populations. Line designations are described in the text. The 13:3 value of S05-37 (3.85) is significant only if Yate's correction (Yates, 1934) is used. Ratio of fertile: sterile plants is F:S.

\begin{tabular}{|c|c|c|c|c|c|c|c|c|c|}
\hline & \multirow[b]{2}{*}{$\mathrm{F}: S$} & \multicolumn{8}{|c|}{ Ratio tested } \\
\hline & & $3: 1$ & $9: 7$ & $13: 3$ & $15: 1$ & $63: 1$ & $1: 1$ & $1: 3$ & $1: 7$ \\
\hline \multicolumn{10}{|l|}{ M18 Lines } \\
\hline $\mathrm{F}_{4}(\mathrm{SO} 4-28)$ & $61: 31$ & 3.71 & 3.78 & ** & $* *$ & $\star *$ & & & \\
\hline $\mathrm{BC}_{2} \mathrm{~F}_{1}(\mathrm{SO} 4-29)$ & $11: 48$ & & & & & & $* *$ & 1.27 & 2.04 \\
\hline $\mathrm{BC}_{1} \mathrm{~F}_{2}(\mathrm{SO} 4-30)$ & $54: 34$ & ** & 0.94 & ** & ** & ** & & & \\
\hline $\mathrm{BC}_{1} \mathrm{~F}_{3}(\mathrm{~S} 05-35)$ & $42: 29$ & ** & 0.24 & ** & ** & ** & & & \\
\hline $\mathrm{BC}_{2} \mathrm{~F}_{1}(\mathrm{~S} 05-36)$ & 9:47 & & & & & & ** & 2.38 & 0.65 \\
\hline $\mathrm{BC}_{1} \mathrm{~F}_{3}(\mathrm{~S} 05-37)$ & $52: 20$ & 0.30 & ** & $*(3.85)$ & ** & $\star *$ & & & \\
\hline $\mathrm{BC}_{2} \mathrm{~F}_{1}(\mathrm{~S} 05-38)$ & $8: 56$ & & & & & & ** & * & 0.00 \\
\hline $\mathrm{BC}_{2} \mathrm{~F}_{1}(\mathrm{~S} 06-17)$ & $15: 0$ & & & & & & & & \\
\hline $\mathrm{BC}_{2} \mathrm{~F}_{1}(\mathrm{~S} 06-19)$ & $14: 0$ & & & & & & & & \\
\hline \multicolumn{10}{|l|}{ M21 Lines } \\
\hline $\mathrm{F}_{4}(\mathrm{~S} 01-30)$ & $36: 3$ & * & ** & 3.13 & 0.14 & ** & ** & & \\
\hline $\mathrm{F}_{4}(\mathrm{SO} 04-25)$ & $29: 1$ & ** & ** & * & 0.44 & 0.65 & & & \\
\hline $\mathrm{BC}_{1} \mathrm{~F}_{1}(\mathrm{~S} 03-25)$ & $62: 0$ & & & & & & & & \\
\hline $\mathrm{BC}_{2} \mathrm{~F}_{1}(\mathrm{~S} 04-26)$ & $5: 26$ & & & & & & $* *$ & 1.30 & 0.37 \\
\hline $\mathrm{BC}_{2} \mathrm{~F}_{1}(\mathrm{SO} 4-27)$ & $2: 38$ & & & & & & ** & $\star \star$ & 2.06 \\
\hline
\end{tabular}

*Significant at the 0.05 probability level.

${ }^{*}$ Significant at the 0.01 probability level.

by IS1112C (Tang et al., 1998; Tang and Pring, 2003). The population segregated for fertile and sterile plants, but we were unable to obtain an accurate ratio because of extensive tillering. Fertile plants in this population had a mean seed set of $77 \%$. Analysis of the $\mathrm{BC}_{2} \mathrm{~F}_{1}$ S04-29 population indicated 11F:48S plants, with a highly variable percentage seed set among the fertile plants, ranging from 1 to $80 \%$ (Table 1). Chi-square analysis indicates that the data fit 1:3 and 1:7 ratios (Table 2). Examinations of 14 plants revealed a low percentage of stained pollen, with only 1 plant carrying $50 \%$ stained pollen, in contrast to the $\mathrm{BC}_{1} \mathrm{~F}_{1}$. The $\mathrm{BC}_{1} \mathrm{~F}_{2} \mathrm{~S} 04-30$ population segregated 54F:34S, with seed set among the fertile plants skewed toward high percentages (Table 1). Chi-square data indicates that the data fit a 9:7 ratio (Table 2). The $\mathrm{BC}_{1} \mathrm{~F}_{3} \mathrm{~S} 05-35$ population segregated 42F:29S, with seed set distribution among the fertile plants similar to that of the parental $\mathrm{BC}_{1} \mathrm{~F}_{2} \mathrm{~S} 04-30$ (Table 1). Chi-square analyses fit a 9:7 ratio (Table 2), as did the data from the parental $\mathrm{BC}_{1} \mathrm{~F}_{2} \mathrm{~S} 04-30$. The $\mathrm{BC}_{2} \mathrm{~F}_{1}$ S05-36 population segregated 9F:47S (Table 2), which fit $1: 3$ and 1:7 ratios, paralleling data derived from the $\mathrm{BC}_{2} \mathrm{~F}_{1}$ S04-29. Among the nine fertile $\mathrm{BC}_{2} \mathrm{~F}_{1}$ S05-36 plants, percentage seed set was 1 to $70 \%$, with a distribution similar to that of the $\mathrm{BC}_{2} \mathrm{~F}_{1}$ S04-29. Thirty-six $\mathrm{BC}_{2} \mathrm{~F}_{1}$ S05-36 individuals were examined for pollen staining, and only two showed at least $50 \%$ stained pollen, similar to data from the $\mathrm{BC}_{2} \mathrm{~F}_{1}$ S04-29 population.
The $\mathrm{BC}_{1} \mathrm{~F}_{3} \mathrm{~S} 05-37$ population (derived from a second $\mathrm{BC}_{1} \mathrm{~F}_{2}$ S04-30 individual) segregated 52F:20S with a $79 \%$ percentage seed set skewed toward high percentages (Table 1). The segregation data fit a 3:1 and a 13:3 (two-gene) model, the latter only if Yates (1934) correction was utilized (Table 2). The corresponding $\mathrm{A} 3 \mathrm{Tx} 398$ backcross $\mathrm{BC}_{2} \mathrm{~F}_{1} \mathrm{~S} 05-38$ population segregated 8F:56S, with a seed set pattern similar to other backcross $F_{1}$ 's examined (Table 1). These segregation data fit only a 1:7 ratio (Table 2). Forty-six $\mathrm{BC}_{2} \mathrm{~F}_{1} \mathrm{~S} 05-$ 38 individuals were examined, and only 5 had at least 50\% stained pollen. Thus, each of three $\mathrm{BC}_{2} \mathrm{~F}_{1}$ progenies had a lower percentage stained pollen percentage than the $\mathrm{BC}_{1} \mathrm{~F}_{1}$.

Seed set among 14M18 progenies exhibited a trend toward higher percentage seed set among fertile members of the $\mathrm{F}_{2}$ and $\mathrm{F}_{3}$ populations (S04-30, 61\%; S05-35, 67\%; S05-37, 79\%), similar to the parental population (S04-28, $68 \%)$, than observed for the backcross $\mathrm{BC}_{2} \mathrm{~F}_{1}$ populations (S04-29, 38\%; S05-36, 29\%; S05-38, 44\%) (Table 1).

To develop lines homozygous for the putative restorers we advanced the $\mathrm{BC}_{1} \mathrm{~F}_{3}$ population $\mathrm{S} 05-37$ by selection and self-pollination. Among $16 \mathrm{BC}_{1} \mathrm{~F}_{4}$ families examined, only 1 family showed no segregation for sterile plants. Two members of this family were self-pollinated, and each of 25 and 26 progeny from the two $\mathrm{BC}_{1} \mathrm{~F}_{5}$ lines showed $100 \%$ pollen staining, indicating that the parental plants were homozygous for the restoring alleles. The two parental plants were backcrossed to A3Tx398, generating $\mathrm{BC}_{2} \mathrm{~F}_{1}$ 's S06-17 and S06-19. Pollen staining of S06-17 showed 5 plants with $50 \%$ staining and 11 plants with 75\% staining, while S06-19 showed 3 plants with 25\% staining, 11 plants with 50\% staining, and 2 plants with $75 \%$ staining. Staining patterns of these $\mathrm{F}_{1}$ 's, specifically members of the populations with greater than $50 \%$ pollen staining, do not resemble characteristics of gametophytic restoration conferred by IS1112C (Tang et al., 1998; Tang and Pring, 2003). Seed set in the two $\mathrm{BC}_{2} \mathrm{~F}_{1}$ 's was 70 and $71 \%$ (Table 1), with no male-sterile plants.

\section{Evaluation of 14M21 Progeny}

Evaluations of 14M21 progeny were more limited because variability among the progenies examined did not allow consistent interpretations in terms of the characteristics of fertility restoration. The $\mathrm{F}_{4}$ was evaluated in two separate years, and progeny segregated 36F:3S and 29F:1S, respectively, with highly variable seed set averaging 72 and $64 \%$ (Table 1). Segregation ratios fit 13:3 and 15:1 ratios for the first year data, and 15:1 and 63:1 ratios for the second-year data (Table 2). Sixty-two plants were evaluated in the $\mathrm{BC}_{1} \mathrm{~F}_{1}$ S03-25 population; all were fertile with an average of $83 \%$ seed set (Table 1). Sixty-one were examined for pollen staining, and 49 had 50 to $100 \%$ stained pollen, similar to staining data from the $\mathrm{BC}_{1} \mathrm{~F}_{1}$ developed from $14 \mathrm{M} 18$.

Subsequent backcrosses, however, provided variable results. Among the $\mathrm{BC}_{1} \mathrm{~F}_{1} \mathrm{~S} 03-25$ progeny, the individual 25-69 had 80\% pollen staining and 30\% seed set. 
When A3Tx398 was pollinated with 25-69 to generate the $\mathrm{BC}_{2} \mathrm{~F}_{1} \mathrm{~S} 04-26$, the resultant population segregated $5 \mathrm{~F}: 26 \mathrm{~S}$, and the five fertile plants had only $30 \%$ seed set (Table 1). Chi-square analyses indicate that these data fit 1:3 and 1:7 models (Table 2). A second backcross was made with individual $25-72$, which had $80 \%$ pollen staining and $90 \%$ seed set, to generate the $\mathrm{BC}_{2} \mathrm{~F}_{1}$ S04-27, which segregated $2 \mathrm{~F}: 38 \mathrm{~S}$, fitting a 1:7 ratio, and the two fertile plants had an estimated $1 \%$ seed set (Table 2), rendering these of questionable value. Progeny from these two backcrosses thus had low seed set percentages, paralleling observations of backcrosses with the 14M18 populations.

\section{Transcript Analyses}

We examined individuals and populations derived from the sudangrass pollinations for enhanced orf107 TPA, thought to be tightly linked to, or to represent action of the $R f 3$ restoring allele (Tang et al., 1996b, 1998; Pring et al., 1999). Members of the original $F_{1}$ population resulting from pollination of A3Tx398 with the sudangrass lines NP28S $-1, N_{1} 28 S_{1}-2, N_{2} 25 S_{1}-1$, and NP35S -2 , and bulk seedlings of the $\mathrm{F}_{2}$ 's, were scored for enhanced orf107 TPA and for activity of Mmt1. None of the lines exhibited enhanced orf107 TPA (not shown), indicating that the restoration mechanism did not involve altered orf107 transcripts. Some of the $\mathrm{F}_{1}$ individuals exhibited Mmt1, indicating that the sudangrass populations were heterogenous for the presence of Mmt1 (data not shown).

Six fertile members of advanced progenies derived from 14M18, selected by scoring for percentage stained pollen before leaf RNA isolation, were individually examined for enhanced orf107 TPA. Two individuals from the $\mathrm{BC}_{1} \mathrm{~F}_{1}$ S05-37 (Fig. 1A, F), three individuals from the $\mathrm{BC}_{2} \mathrm{~F}_{1}$ S05-38 (Fig. 1B, C, G), and one individual from the $\mathrm{BC}_{2} \mathrm{~F}_{1}$ S05-36, each exhibited abundant 1110-, 870-, and 810-nt whole-length (Tang et al., 1996a) orf107 transcripts, along with a trace of the processed 380-nt transcript resulting from basal level processing. None of the individuals showed evidence of enhanced TPA resulting in the accumulation of the 380-nt product, such as shown for a male-fertile $\mathrm{BC}_{15} \mathrm{~F}_{2}$ derived from A3Tx398/IS1112C (Pring and Tang, 2004; Pring et al., 2006)(Fig. 1D).

Six fertile members of the 14M18-derived populations were also examined for action of $M m t 1$, linked to enhanced orf107 TPA in IS1112C (Tang et al., 1996a, 1998), which conditions enhanced cleavage of a 1044-nt atp 4 transcript, generating a 832-nt transcript. A male-fertile Mmt1 $\mathrm{BC}_{11} \mathrm{~F}_{3}$ resulting from pollination of A3Tx398 with IS1112C (Pring and Tang, 2004; Pring et al., 2006) exhibited the 1044-nt transcript and abundant levels of the processed 832-nt transcript (Fig. 2A), while A3Tx398 (mmt1) displayed only a trace of the processed transcript (Fig. 2B). Three individuals from the $\mathrm{BC}_{1} \mathrm{~F}_{3} \mathrm{~S} 05-37$ (Fig. $2 \mathrm{C}, \mathrm{F}, \mathrm{G}$ ), two individuals from the $\mathrm{BC}_{2} \mathrm{~F}_{1}$ S05-38 (Fig.

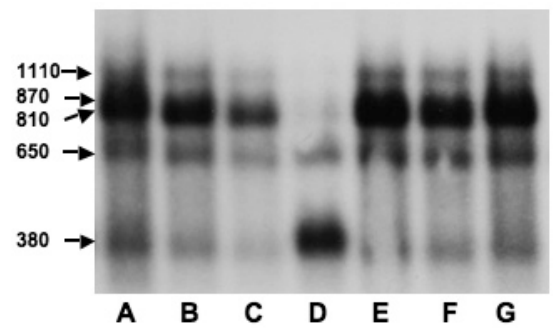

Figure 1. Transcript analyses for enhanced mitochondrial orf107 transcript processing. Total leaf RNAs were prepared, and RNA from $2.5 \mathrm{~g}$ tissue was blotted to membranes and probed with the orf107 clone pHC104, which spans orf107 and carries sequences of atp9 (Tang et al., 1996b). A. S05-37, \#38; B. S05-38, \#40; C. S05-38, \#49; D. a male-fertile BC15F2 resulting from pollination of A3Tx398 with IS1112C; E. S05-36, \#176; F. S05-37, \#67; and G. S05-38, \#48. The 1110-, 870-, and 810-nt transcripts represent whole-length orf107 transcripts, while the 380-nt transcript results from processing. The 650-nt transcript is derived from atp9.

$2 \mathrm{D}, \mathrm{H}$ ), and one individual from the $\mathrm{BC}_{2} \mathrm{~F}_{1} \mathrm{~S} 05-36$ (Fig. $2 \mathrm{E})$, each displayed abundant levels of the 832-nt processed transcript, indicating that all plants were Mmt1. Although the sudangrass-derived fertility restoration is associated with the presence of Mmt1, linked to enhanced orf107 TPA in IS1112C, the latter is not expressed in these lines, and thus we conclude that the mechanism of fertility restoration in A3Tx398 derived from the sudangrass populations does not involve enhanced orf107 TPA.

\section{Phenotypic Expression of Male Fertility Restoration Conferred by Sudangrass}

Male-sterile sorghum carrying IS1112C cytoplasm is associated with exsertion of turgid anthers filled with noniodine-staining pollen with a diameter about $90 \%$ that of pollen from normal, fertile plants (Tang et al., 1998). Heterozygous $F_{1}$ 's exhibit a mixture of iodine-stained and unstained pollen grains. We observed a similar phenotypic expression of CMS in lines segregating for fertility/ sterility in the sudangrass-derived progeny, wherein many plants exserted anthers that carried mixtures of stained and unstained pollen. In segregating progeny from a selfpollinated S05-37 individual, a male-fertile plant scored

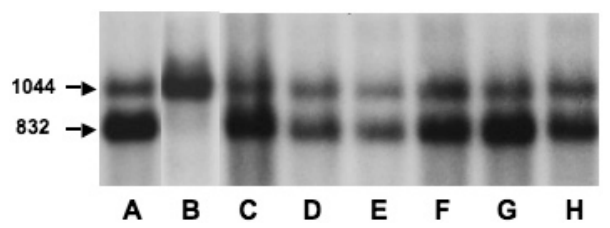

Figure 2. Transcript analyses for action of $\mathbf{M m t 1}$. Total leaf RNAs were prepared, and RNA from $2.5 \mathrm{~g}$ tissue was blotted to membranes and probed with the atp4 clone pHT160 (Tang et al., 1996a). A. Male-fertile BC11F3 resulting from pollination of A3Tx398 with IS1112C; B. A3Tx398; C. S05-37, \#30; D. S05-38, \#40; E. S05-36, \#167; F. S05-37, \#167; G. S05-37, \#67; and H. S05-38, \#48. The population of 1044-nt transcripts is partially cleaved in the presence of $\mathrm{Mmt1}$, generating the 832-nt transcript. 


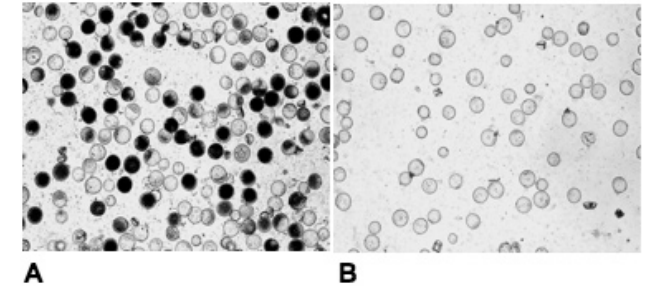

Figure 3. lodine staining of pollen from self-pollinated progeny of the BC1F3 S05-37. (A) Male-fertile plant, (B) male-sterile segregant. Note similarity in size of stained and unstained pollen in (A), and low frequency of collapsed unstained pollen in (A) and (B).

as $50 \%$ stained pollen (Fig. 3A) included turgid, near-fullsized nonstaining pollen, and a male-sterile plant (Fig. 3B) was characterized by turgid, nonstaining pollen.

\section{DISCUSSION}

The recovery of sudangrass-derived fertility restoration capability for the A3 male-sterile sorghum cytoplasm, first observed by Pedersen and Toy (1997), and further developed here, identifies possible alternative approaches to developing the A3 cytoplasm for utilization in hybrid development. In addition to the low frequency of restorer genes in sorghum germplasm, the low percentage seed set in heterozygous $\mathrm{F}_{1}$ 's restored to fertility with IS1112C, 50 to $61 \%$ (Worstell et al., 1984; this work), represents a barrier in utilization of the A3 male-sterile cytoplasm for seed production. Alternatively, even low levels of viable pollen may increase risk of unwanted gene flow in a pollination control system based on A3 CMS as described by Pedersen et al. (2003). If fertility restoration can be conferred by sudangrass or shattercane, gene flow could potentially occur via fertile progeny from cultivated sorghum $\times$ uncontrolled sudangrass or shattercane (taxonomically the same subspecies) crosses.

The appearance of male-sterile individuals in segregating backcross, $\mathrm{F}_{2}$, and $\mathrm{F}_{3}$ populations derived from sudangrass indicates that the mechanism of restoration is sporophytic, wherein the diploid genotype determines pollen viability. This possibility was first apparent in the occurrence of up to $37 \%$ male-sterile individuals in $\mathrm{F}_{2}$ families derived from pollination of A3Tx398, with the bulked sudangrass lines, and observed in progenies derived from 14M18 and 14M21. These data are in marked contrast to gametophytic restoration conferred by IS1112C (Tang et al., 1996b, 1998; Pring et al., 1999), wherein male-sterile individuals occur at very low frequency in backcrosses and $\mathrm{F}_{2}$ 's. Compilation of data from A3Tx398/IS1112C $\mathrm{F}_{2}$ 's grown in Gainesville, FL, College Station, TX, and Mayaguez, Puerto Rico, 19901995, identified only four male-sterile plants among 430 plants examined (unpublished data, 2006). Thus it is clear the mechanism of sudangrass-derived fertility restoration, at least as evaluated in A3Tx398, is distinct from the previously described restoration conferred by IS1112C. Addi- tionally, sudangrass-derived restoration does not involve enhanced orf107 TPA, although we have also identified one sorghum line, SC215, that carries a restorer that complements the Rf4 allele but does not confer enhanced orf107 TPA (Kuhlman et al., 2006).

Four other CMS systems (maize, Zea mays L.; common bean, Phaseolus vulgaris L.; rice, Oryza sativa L.; and cotton, Gossypium hirsutum L.) exhibit multiple, independent mechanisms of fertility restoration. Of these, cotton offers a precedent for gametophytic and sporophytic fertility restoration mechanisms for a male-sterile cytoplasm of higher plants, as developed for the $\mathrm{D}_{8}$ cytoplasm, wherein the $R f 1$ gene restores fertility through a sporophytic mechanism, and $R f 2$, through a gametophytic mechanism (Zhang and Stewart, 2001; Feng et al., 2005). At the molecular level, the alternative maize (Wen et al., 2003), common bean (He et al., 1995; Sarria et al., 1998), and rice (Wang et al., 2006) restoration systems restrict expression of mitochondrial CMS loci by different molecular mechanisms. These mechanisms include changes in mitochondrial DNA organization, transcript accumulation, transcript processing, and protein stability. Fertility restoration mechanisms therefore reveal the complex events of plant mitochondrial gene expression regulated by nuclear restorer alleles. The molecular mechanism of fertility restoration by sudangrass appears to be posttranscriptional. Further investigation into this mechanism will provide additional insights into the causal mechanism of A3 CMS.

Estimates of the genetic complexity of restoration derived from the $14 \mathrm{M} 18$ sudangrass derivative were not entirely consistent. Segregation patterns of the original $\mathrm{F}_{4}$ population S04-28 fit a one gene (3:1) and a two-gene complementary (9:7) sporophytic model, while the $\mathrm{BC}_{1} \mathrm{~F}_{2}$ S04-30 and the $\mathrm{BC}_{1} \mathrm{~F}_{3}$ S05-35 populations fit only the latter, two-gene model. The $\mathrm{BC}_{1} \mathrm{~F}_{3} \mathrm{~S} 04-37$, derived from a different $\mathrm{F}_{2}$ individual than was used for the $\mathrm{BC}_{1} \mathrm{~F}_{3}$ S05-35, was consistent with a sporophytic one-gene 3:1 pattern, and a two-gene 13:3 pattern if the Yates (Yates, 1934) correction was utilized. Therefore the original $14 \mathrm{M} 18 \mathrm{~F}_{4}$ population, the derived $\mathrm{BC}_{1} \mathrm{~F}_{2} \mathrm{~S} 04-30$, and the $\mathrm{BC}_{1} \mathrm{~F}_{3} \mathrm{~S} 05-35$ share a 9:7 two-gene complementary action model, and the two backcrosses S04-29 and S05-36 segregated as one or two genes.

Confounding these conclusions are observations that the sudangrass-derived restorers may not be efficacious, indicated by less than $100 \%$ stained pollen in progeny of A3Tx398 pollinated with certain of the developed lines. Decreases in pollen stainability were particularly evident in backcross generations. Three $\mathrm{BC}_{2} \mathrm{~F}_{1}$ populations derived from $14 \mathrm{M} 18$ exhibited $50 \%$ or less stained pollen, which mimics aspects of gametophytic restoration patterns for the A3 male-sterile cytoplasm, wherein 50 and $25 \%$ stainability are observed, dependent on the requirement of one or two restorer genes, respectively (Tang et al., 1998; Tang 
and Pring, 2003). We were able to reproduce the phenomenon of less than 100\% stained pollen in backcross progeny with the two $\mathrm{BC}_{1} \mathrm{~F}_{4}$ lines apparently homozygous for the required restoring alleles. The $\mathrm{BC}_{2} \mathrm{~F}_{1}$ progeny lines S06-17 and S06-19 displayed a range of 25 to $75 \%$ pollen staining, similar to observations with $14 \mathrm{M} 18$ as a pollen parent. Associated with this decrease in pollen stainability is reduced seed set among 14M18-derived backcross populations compared to $\mathrm{BC}_{1} \mathrm{~F}_{2}$ and $\mathrm{BC}_{1} \mathrm{~F}_{3}$ generations. Specifically, the three $\mathrm{BC}_{2} \mathrm{~F}_{1}$ populations derived from $14 \mathrm{M} 18$ displayed lower percentage stained pollen and reduced mean seed set compared to a $\mathrm{BC}_{1} \mathrm{~F}_{1}$ and three $\mathrm{BC}_{1} \mathrm{~F}_{2}$ and $\mathrm{BC}_{1} \mathrm{~F}_{3}$ populations. This phenomenon, decreased seed set associated with backcross generations compared to selfpollinated generations, has also been observed for rice carrying the Chinsurah boro II male-sterile cytoplasm (Sano et al., 1992). These factors may have contributed to the high frequency of male-sterile plants in the three $\mathrm{BC}_{2} \mathrm{~F}_{1}$ populations. These effects were not manifested in the $\mathrm{BC}_{2} \mathrm{~F}_{1}$ progeny lines S06-17 and S06-19, derived from the apparent homozygous parent, wherein seed set was comparable to that of $\mathrm{BC}_{1} \mathrm{~F}_{2}$ and $\mathrm{BC}_{1} \mathrm{~F}_{3}$ populations, and no male-sterile plants were observed.

The partial pollen staining and low seed sets observed in populations segregating for restoring alleles derived from sudangrass could result from a requirement for restoring alleles at minor-effect loci that sort independently from the major-effect restorer genes, such that full fertility is recovered only when all major- and minor-effect restoring alleles are present. Fully fertile $\mathrm{BC}_{1} \mathrm{~F}_{1}$ plants might be heterozygous for restoring alleles at each of the required major and minor restoration loci. Segregation and independent assortment would then produce $\mathrm{BC}_{2} \mathrm{~F}_{1}$ plants inheriting only a subset of the alleles needed to achieve full fertility. Perhaps the absence of all minor-effect restoring alleles accounts for the excess of male-sterile progeny in advanced backcross families. $\mathrm{BC}_{1} \mathrm{~F}_{2}$ plants derived by self-pollination of fully fertile $\mathrm{BC}_{1} \mathrm{~F}_{1}$ plants have a higher probability of inheriting a restoring allele at each of the major- and minor-effect loci, and segregants homozygous for restoring alleles at all loci might be recovered. Fully fertile $\mathrm{BC}_{1} \mathrm{~F}_{5}$ plants derived from S05-37 were probably homozygous for restoring alleles at most, if not all, of the major and minor restorer loci. The S06-17 and S06-19 $\mathrm{BC}_{2} \mathrm{~F}_{1}$ progeny were therefore expected to inherit a full set of major and minor restoring alleles. The absence of male-sterile plants in these populations is consistent with fertility restoration conditioned by major and minor gene effects, although the highly variable pollen staining among the progeny would require invoking heterozygosity of the $\mathrm{BC}_{1} \mathrm{~F}_{5}$ parents.

Alternatively, silencing of a restoring allele following fertilization of an egg carrying a nonrestoring allele could account for reduced pollen stainability and the recovery of excess male-sterile progeny in $\mathrm{BCF}_{1}$ populations.
Silencing of an active allele following association with an inactive allele is a feature of paramutation, first investigated in maize (Brink et al., 1968). Paramutation is an epigenetic phenomenon, and the rates of gene silencing are variable and allele specific, with penetrance ranging from 10 to 100\% (Chandler and Stam, 2004). In the present context, the frequency of male-fertile plants in $\mathrm{BCF}_{1}$ populations would depend largely on the efficiency with which a pollen-transmitted restoring allele is silenced by the female-contributed nonrestoring allele. Silencing that occurs during plant development, before gamete formation, might result in sectored anthers that produced both stained and unstained pollen, thereby accounting for the variable frequency of pollen staining observed among $\mathrm{BCF}_{1}$ plants, particularly for the S06-17 and S06-19 BC $\mathrm{F}_{2}$ populations. The effects of silencing would be less apparent in $\mathrm{F}_{2}$ or $\mathrm{F}_{3}$ populations because a significant fraction of the female gametes producing these populations also carry restoring alleles.

Documentation of a novel fertility restoration mechanism for the A3 male-sterile cytoplasm raises the possibility of development of a system useful in exploiting this source of CMS. Instability of restorer function, as defined in the Tx398 background, and particularly in backcrosses, represents a potential barrier to utilization. Other lines, however, may not carry paramutagenic alleles, as defined by Chandler and Stam (2004), and thus not exhibit instability in fertility restoration. Development of markers linked to the restorer loci will facilitate introgression of the loci into other agronomic lines to further evaluate the utility of this system.

\section{Acknowledgments}

We thank Drs. P.S. Chourey and C.E.Vallejos for critical reviews and acknowledge the technical assistance of Odenis Vitorelli. This was a cooperative investigation of the USDA-ARS and the Institute of Food and Agricultural Sciences, University of Florida.

\section{References}

Bosques-Vega, A., A. Sotomayor-Rios, S. Torres-Cardona, H.R. Perrerly, and K.F. Schertz. 1989. Maintainer and restorer reaction with A1, A2, and A3 cytoplasms of lines from the sorghum conversion program. Texas Agric. Exp. Sta. Misc. Pub. 1976. Texas A\&M Univ., College Station.

Brink, R.A., E.D. Styles, and J.D. Axtell. 1968. Paramutation: Directed genetic change. Science 159:161-170.

Chandler, V.L., and M. Stam. 2004. Chromatin conversations: Mechanisms and implications of paramutation. Nat. Rev. Genet. 5:532-544.

Feng, C.D., J.M. Stewart, and J.F. Zhang. 2005. STS markers linked to the Rf1 fertility restorer gene of cotton. Theor. Appl. Genet. 110:237-243.

Gorz, H.J., F.A. Haskins, and K.P. Vogel. 1990a. NP28 low-dhurrin sudangrass germplasm. Crop Sci. 30:758.

Gorz, H.J., F.A. Haskins, and K.P. Vogel. 1990b. NP33, NP34, and NP35 sudangrass germplasm. Crop Sci. 30:760. 
He, S., A. Lyznik, and S. Mackenzie. 1995. Pollen fertility restoration by nuclear gene Fr in CMS bean: Nuclear-directed alteration of a mitochondrial population. Genetics 139:955-962.

Kim, J.-S., P.E. Klein, R.R. Klein, H.J. Price, J.E. Mullet, and D.M. Stelly. 2005. Chromosome identification and nomenclature of sorghum bicolor. Genetics 169:1169-1173.

Kuhlman, L.C., D.R. Pring, W.L. Rooney, and H.V. Tang. 2006. Allelic frequency at the $R f 3$ and $R f 4$ loci and the genetics of A3 cytoplasmic fertility restoration in converted sorghum lines. Crop Sci. 46:1576-1580.

Pedersen, J.F., D.B. Marx, and D.L. Funnell. 2003. Use of $\mathrm{A}_{3}$ cytoplasm to reduce risk of gene flow through sorghum pollen. Crop Sci. 43:1506-1509.

Pedersen, J.F., and J.J. Toy. 1997. Forage yield, quality, and fertility of sorghum $\times$ sudangrass hybrids in $A_{1}$ and $A_{3}$ cytoplasm. Crop Sci. 37:1973-1997.

Pring, D.R., and H.V. Tang. 2004. Transcript profiling of malefertile and male-sterile sorghum indicates extensive alterations in gene expression during microgametogenesis. Sex. Plant Reprod. 16:289-297.

Pring, D.R., H.V. Tang, C.D. Chase, and M.N. Siripant. 2006. Microspore gene expression associated with cytoplasmic male sterility and fertility restoration in sorghum. Sex. Plant Reprod. 19:25-35.

Pring, D.R., H.V. Tang, W. Chen, W. Howad, and F. Kempken. 1999. A unique two-gene gametophytic male sterility system in sorghum involving a possible role of RNA editing in fertility restoration. J. Hered. 90:386-393.

Pring, D.R., H.V. Tang, and K.F. Schertz. 1995. Cytoplasmic male sterility and organelle DNAs of sorghum. p. 461-495. In C.S. Levings III and I. K. Vasil (ed.) The molecular biology of plant mitochondria. Kluwer Academic, Dordrecht, the Netherlands.

Sano, Y., M. Eiguchi, H.Y. Hirano, and M.A. Yamada. 1992. A nuclear gene modifying instability of fertility restoration in cytoplasmic male sterile rice. Genet. Res. 60:195-200.

Sarria, R., A. Lyznik, C.E. Vallejos, and S.A. Mackenzie. 1998. A cytoplasmic male sterility-associated mitochondrial peptide is common bean is post-translationally regulated. Plant Cell 10:1217-1228.

Schertz, K.F., S. Sivaramakrishnan, W.W. Hanna, J. Mullet, Y. Sun, U.R. Murty, D.R. Pring, K.N. Rai, and B.V.S. Reddy. 1997. Alternate cytoplasms and apomixis of sorghum and pearl millet. p. 213-223. In Proc. Intl. Conf. Genetic Improvement of Sorghum and Pearl Millet. INTSORMIL/ ICRISAT, Lubbock, TX.
Tang, H.V., R. Chang, and D.R. Pring. 1998. Cosegregation of single genes associated with fertility restoration and transcript processing of sorghum mitochondrial orf107 and urf 209. Genetics 150:383-391.

Tang, H.V., and D.R. Pring. 2003. Conversion of fertility restoration of the sorghum IS1112C $\left(\mathrm{A}_{3}\right)$ male-sterile cytoplasm from two genes to one gene. Crop Sci. 43:1747-1753.

Tang, H.V., D.R. Pring, F.R. Muza, and B. Yan. 1996a. Sorghum mitochondrial orf25 and a related chimeric configuration of a male-sterile cytoplasm. Curr. Genet. 29:265-274.

Tang, H.V., D.R. Pring, L.C. Shaw, F.A. Salazar, F.R. Muza, B. Yan, and K.F. Schertz. 1996b. Transcript processing internal to a mitochondrial open reading frame is correlated with fertility restoration in male-sterile sorghum. Plant J. 10:123-133.

Torres-Cardona, S.A., A. Sotomayor-Rios, A. Quiles Belén, and K.F. Schertz. 1990. Fertility restoration to A1, A2, and A3 cytoplasm systems of converted sorghum lines. Texas Agric. Exp. Sta. Misc. Pub. 1721. Texas A\&M Univ., College Station.

Wang, Z., Y. Zou, X. Li, Q. Zhang, L. Chen, H. Wu, D. Su, Y. Chen, J. Guo, D. Luo, Y. Long, Y. Zhong, and Y.G. Liu. 2006. Cytoplasmic male sterility of rice with boro II cytoplasm is caused by a cytotoxic peptide and is restored by two related PPR motif genes via distinct modes of mRNA silencing. Plant Cell 18:676-687.

Wen, L., K.L. Ruesch, V.M. Ortega, T.L. Kamps, S. GabayLaughnan, and C.D. Chase. 2003. A nuclear restorer of fertility mutation disrupts accumulation of mitochondrial ATP synthase subunit A in developing pollen of S male-sterile maize. Genetics 165:771-779.

Wen, L., H.V. Tang, W. Chen, R. Chang, D.R. Pring, P.E. Klein, K.L. Childs, and R.R. Klein. 2002. Development and mapping of AFLP markers linked to the sorghum fertility restorer gene rf4. Theor. Appl. Genet. 104:577-585.

Worstell, J.V., H.J. Kidd, and K.F. Schertz. 1984. Relationships among male-sterility inducing cytoplasms of sorghum. Crop Sci. 24:186-189.

Xu, G.-W., Y.-X. Cui, K.F. Schertz, and G.E. Hart. 1995. Isolation of mitochondrial DNA sequences that distinguish male-sterility-inducing cytoplasms in Sorghum bicolor (L.). Moench. Theor. Appl. Genet. 90:1180-1187.

Yates, F. 1934. Contingency tables involving small numbers and the $\chi^{2}$ test. J. R. Stat. Soc. [Ser A] 1(Suppl.):217-235.

Zhang, J.R., and J.M. Stewart. 2001. Inheritance and genetic relationships of the D8 and D2-2 restorer genes for cotton cytoplasmic male sterility. Crop Sci. 41:289-294. 